\title{
QUESTÕES IDENTITÁRIAS: O SECRETARIADO EXECUTIVO E AS ATIVIDADES TRADUTÓRIAS
}

\section{PROFESSIONAL IDENTITY: EXECUTIVE SECRETARIAT AND THE TRANSLATION ACTIVITIES}

\begin{abstract}
Aline Cantarotti
Doutoranda em Estudos Lingüísticos pela Universidade Estadual Paulista Júlio de Mesquita Filho - UNESP, São Paulo, (Brasil). Docente na Universidade Estadual de Maringá - UEM, Paraná, Brasil. E-mail: licialine@ gmail.com
\end{abstract}




\title{
QUESTÕES IDENTITÁRIAS: O SECRETARIADO EXECUTIVO E AS ATIVIDADES TRADUTÓRIAS
}

\section{RESUMO}

Questões identitárias nos levam a refletir sobre o que significa ser tradutor para o Secretariado Executivo e o que significa também traduzir para esses profissionais, tema relevante para a formação. Considerando as línguas estrangeiras, corroboramos Rajagopalan (1998) quando ele problematiza uma ação errônea de linguistas os quais não se voltam para os falantes reais, com todas as hibridizações que possuem, com o atravessamento de diferentes perspectivas, culturas e contatos na constituição de uma sociedade. O pluralismo linguístico é um fenômeno social, assim como a constituição de comunidades linguisticamente pluralistas também é e o Secretariado Executivo se insere neste contexto. Tendo em vista que a globalização é contribuinte desse panorama e que a profissão do secretário executivo é globalizada, este estudo objetiva investigar e retratar a identidade do secretário executivo, na perspectiva dos alunos em formação, considerando atividades tradutórias em seu lócus de trabalho. Para tanto, questionários foram aplicados aos alunos em um curso de Secretariado Executivo e suas respostas analisadas qualitativamente. Os futuros secretários percebem a necessidade de estudos na área de tradução e consideram que só poderão executar atividades tradutórias se forem expostos a esses conhecimentos e à sua prática ainda na graduação.

Palavras-Chaves: Estudos da Tradução; Secretariado Executivo; Identidade.

\section{PROFESSIONAL IDENTITY: EXECUTIVE SECRETARIAT AND THE TRANSLATION ACTIVITIES}

\begin{abstract}
Identity issues lead us to reflect on what it means to be a translator for the Executive Secretariat and moreover, what it means to translate for these professionals, relevant topic for teaching and training in translation. Considering foreign languages, we corroborate Rajagopalan (1998) when he discusses an erroneous action of linguists who do not consider the actual speakers, with all the hybridizations they have, with the crossing of different perspectives, cultures and contacts in a society construction and development. The linguistic pluralism is a social phenomenon, as well as the establishment of linguistically pluralistic communities is and the Executive Secretariat is also included in this context. Once globalization is a contributing factor for this scenario and also that the executive secretary professional is globalized, this study aims to investigate and portray the identity of the Executive Secretary on the student perspective in learning and training considering translational activities in their work locus. In order to do so, questionnaires were applied to students in an executive secretariat course and their responses analyzed qualitatively. Future secretaries realize the need for studies in the field of translation and consider that they can only perform translational activities if exposed to this knowledge and its practice still in their undergraduate studies.
\end{abstract}

Keywords: Translation studies; Executive secretariat; Identitiy. 


\section{INTRODUÇÃO}

Com o advento da globalização, o mercado mundial tem estreitado cada vez mais suas relações, e em decorrência disso, a necessidade de o secretário executivo ter conhecimento de, no mínimo, uma língua estrangeira, sendo preferencialmente a língua inglesa além da sua materna, torna-se cada vez mais exigida pelas organizações que mantêm relações exteriores ou internacionais.

Em consequência do quadro descrito, o secretário executivo exerce o papel de facilitador da comunicação nas empresas, sendo o elo entre os clientes e diversos ramos de atividades da empresa, tendo como uma das responsabilidades conhecer e primar pelo bom relacionamento com todos. Cabe ao secretário executivo na sua atuação diária, eventualmente, realizar negociações internacionais, ser intérprete e fazer versões e traduções de documentos, para que dessa forma consiga atender às necessidades de caráter internacional na qual a empresa integra.

Há profissões que atuam em atividades de tradução, apesar de não serem profissionais tradutores, tais como: profissionais da área do comércio exterior, administração financeira, turismo, direito internacional e secretariado executivo, para nomear alguns. Dessa forma, considerando que os Estudos da Tradução são abordados em diversos âmbitos e que é necessário adequar seu ensino ao objetivo da área de aprendizagem, proponho uma reflexão sobre a formação em tradução que atenda às necessidades do Secretariado Executivo.

Um primeiro caminho para essa reflexão seria a discussão sobre a identidade do que chamo de "secretário/tradutor" ainda na formação (durante a graduação). Assim, proponho as seguintes questões: como contribuir para a construção de uma concepção de tradução e de tradutor? Como subsidiar reflexões sobre as teorias de tradução como forma/meio de constituir sua tarefa tradutória? O que significa traduzir para o profissional de Secretariado (meio este que difere daquele do tradutor profissional)? Em que medida e como considerar o papel do currículo e da universidade nesta formação?

Com o objetivo de responder tais questões, tomo como base as questões de constituição/ formação de identidade (Hall, 2001; Wyke, 2010; Silva, 2012). Questões identitárias nos levam a refletir sobre o que significa ser tradutor para o Secretariado Executivo e o que significa também traduzir para esses profissionais, tema relevante para a formação. A proposta é um ponto de partida para intervenção ainda na formação. 
O presente estudo está dividido em três partes. Primeiramente, faz-se uma reflexão sobre os conceitos de identidade em seu âmbito geral e também no contexto secretarial. A segunda parte descreve a metodologia usada e a análise e discussão dos dados coletados de questionários aplicados a alunos do curso de graduação em Secretariado Executivo de uma universidade do norte do Paraná. Por fim, encaminho uma reflexão sobre como essa construção identitária é percebida e o que ela nos aponta sobre a formação considerando os Estudos da Tradução para o Secretariado Executivo.

\section{REFERENCIAL TEÓRICO}

\subsection{Questões Identitárias}

Para considerarmos a constituição de nossa identidade, primeiramente devemos lembrar que não somos um ser uno, ou seja, somos atravessados, constituídos constantemente e regularmente por tudo que experienciamos, vivemos (Silva, 2012). Quando pensamos em identidade, pensamos em nossa constituição e no processo de desenvolvimento dessa constituição. Somos constituídos socialmente e culturalmente de diversas maneiras e em uma diversidade de momentos. Além disso, de acordo com Silva (2012, p. 81), “a identidade, tal como a diferença, é uma relação social. Isso significa que sua definição - discursiva e linguística - está sujeita a vetores de força, a relações de poder”. Não são definidas, são impostas. A sociedade nos impele a essa constituição/construção.

Dentro dessa perspectiva e juntamente com a identidade, a diversidade e a diferença partilham do mesmo lócus. Diversidade e diferença são colocadas pela sociedade como merecedoras de tolerância e respeito, ou seja, sob uma perspectiva da aceitação. Silva (2012) indaga se esse posicionamento condiciona a crítica e o questionamento sobre essas relações. Além disso, questiona também as implicações políticas de conceitos como diferença, identidade, diversidade, alteridade mas, antes de tudo, se não seria necessário uma teoria sobre a produção da identidade e da diferença. Indo além, Silva (2012) ainda questiona se tal teoria, vista como processo, não deveria ressaltar primordialmente aspectos que a problematizam, em vez de aceitá-las de modo passivo com configurações preconcebidas.

Identidade e diferença são, inicialmente e aparentemente, dicotômicas. Afirmar a identidade, por exemplo, significa ao mesmo tempo dizer o que sou e o que não sou, porque ao mesmo tempo que incluo características à minha descrição, excluo outras. Assim, se o 
outro tem as características que eu excluí da descrição de quem eu sou, ele é o diferente. Como cita Silva (2012, pg. 82), "a identidade está sempre ligada a uma forte separação entre "nós" e "eles". Essa demarcação de fronteiras, essa separação e distinção, supõem e, ao mesmo tempo, afirmam e reafirmam relações de poder". Essa separação também é classificatória e é por tal classificação que a sociedade se constitui como tal.

Mesmo sob processo classificatório e considerando, como já exposto, as relações de poder, a constituição da identidade necessita da diferença. É na diferença também que eu constituo a minha identidade. Uma identidade aceita por uma maioria rejeita uma minoria diferente ou diferenciada, adversa. E, assim, a identidade se reverbera como natural, normal, desejável e única.

Porém, e quando há o confronto/encontro com a diferença? Se uma identidade só se constitui com a existência da diferença, consequentemente ela está em contato com a diferença. Nesse sentido, conforme Silva (2012), a identidade unificada seria, então, uma fantasia. Se eu interajo com a sociedade, consequentemente, eu interajo com o diferente, e assim me constituo. Nesse sentido, podemos questionar tanto a dicotomia quanto o distanciamento da identidade e da diferença e, assim, voltamos à sugestão de Silva (2012): faz-se necessário problematizar identidade e diferença.

Nessa perspectiva, pensemos então no processo de globalização, processo em constante mutação e que impacta também a constituição da identidade cultural. Na sociedade globalizada, em constante mudança, o ponto de partida para tal constituição é justamente o contato com o diferente e o estreitamento de laços e de espaços com as diferenças. Nos questionamos até se teríamos, então, uma identidade. Hall (2001, p. 17) pondera: "se tais sociedades não se desintegram totalmente não é porque elas não são unificadas, mas porque seus diferentes elementos e identidades podem, sob certas circunstâncias, ser conjuntamente articulados". De qualquer forma, "a estrutura da identidade permanece aberta". Se não fosse isso, não teríamos história. Assim, com a globalização, uma identidade em primeira instância chamada de "nacional” estaria, então, em declínio e novas identidades, híbridas, estariam em constituição.

Considerando o acima exposto, como relacionamos identidade e diferença com a atividade tradutória? Em que medida as questões de identidade e diferença agem na construção de concepções e de práticas de tradução?

Antes da atividade tradutória, pensemos na língua: uso de uma língua, falantes, comunidade linguística etc. Conceituamos um falante de português, inglês, italiano e assim 
por diante como se não houvesse, de acordo com Rajagopalan (1998, p. 25) "nenhum problema de qualquer espécie para decidir quem pertence e quem não pertence ao grupo que eles (os linguistas) pretendem identificar e discriminar." É só pensarmos no que discutimos até aqui sobre os termos "identidade" e "diferença" para termos uma noção da proporção em que se problematiza esse quadro. Além disso, Rajagopalan (1998) ainda nos lembra de um outro detalhe: assumirmos que há comunidades de fala homogêneas. Ou seja, o ideal de falante-ouvinte de uma língua e de sua comunidade de fala é realmente apenas isso, ideal. Rajagopalan (1998) problematiza justamente uma ação errônea tomada por linguistas os quais não se voltam para os falantes reais, a meu ver, com todas as hibridizações que possuem, com o atravessamento de diferentes perspectivas, culturas e contatos imbricados na constituição de uma sociedade. O pluralismo linguístico é um fenômeno social, assim como a constituição de comunidades linguisticamente pluralistas também é. Conforme já citado, a globalização contribui com isso. Impossível, hoje, pensarmos em uma outra configuração social em termos linguísticos.

Se pensarmos então que, de acordo com Rajagopalan (1998, p. 29), "a identidade do indivíduo falante ocupa [...] uma posição central na construção da teoria linguística", da mesma forma a discussão sobre identidade e sua construção é imprescindível nos Estudos da Tradução e também na formação de secretários. Da mesma forma que as questões de identidade estão dando contornos aos estudos linguísticos, os Estudos da Tradução também se consolidam nas questões da linguagem $\mathrm{X}$ sujeito, ou melhor, da linguagem \& sujeito (vejo mais como adição do que como distantes ou contrapostas). Afinal, a atividade tradutória não se restringe apenas à língua, ou seja, o produto ou matéria-prima com a qual trabalha, ou ainda o(s) sujeito(s) envolvido(s) de modo separado e estanque.

E, assim, o tradutor, a língua e sua prática sob diferentes nuances, perpassada por diferentes aspectos, constituem a base dos estudos sobre tradução. As questões da identidade e da diferença direcionam-se a outras questões como a ética da tradução, o mercado consumidor (seja o direto ou o indireto bem como os meios de veiculação de traduções), gênero \& minorias, entre outros. Um tradutor, bem como o secretário executivo nas atividades tradutórias, além de trabalhar com a língua e a linguagem, complexas como já são, lida ainda com o ser humano e a sociedade na qual vive esse ser humano e ele mesmo enquanto profissional. Talvez, se traduções e os profissionais que a executam ficassem somente no âmbito da língua e linguagem, sua tarefa e sua prática seriam menos complexas. Sendo tal possibilidade remota, o quadro não é este: práticas tradutórias e profissionais já estão 
inseridas em contexto social. Esse ponto já é um agravante de complicação. Ou também descomplicação. Tudo depende sob qual perspectiva o quadro é analisado.

Considerando os aspectos da atuação do tradutor, Wyke (2010) discute justamente a questão da ética de tradução, entre outros assuntos. Na mesma perspectiva de Venutti (2002, p. 156) para o qual "uma ética tradutória não pode se restringir a uma noção de fidelidade", Wyke problematiza as questões de fidelidade, por exemplo, citando códigos de ética e conduta de organizações que salientam, inclusive, a imparcialidade do tradutor em seu texto traduzido ou em sua interpretação oral (como se essa imparcialidade fosse possível, conforme já discutido e corroborando alguns pontos levantados por Rajagopalan). O tradutor, originariamente, pode ser fiel ao texto de partida ou ao texto de chegada, remetendo-se ao seu leitor. Mesmo assim, de acordo com Wyke (2010, p.112), "o fato de que tradutores devem decidir se serão orientados, por exemplo, pelo texto de partida ou de chegada enquanto buscam reproduzir o mesmo texto em outra língua já implica um certo grau de visibilidade por sua parte" (tradução da autora) ${ }^{1}$. Assim, espera-se que o secretário executivo esteja preparado para trabalhar com tais questões.

Ainda de acordo com Wyke (2010), especialmente na segunda metade do século XX, ao invés da imposição de que o tradutor reproduza, sendo ainda neutro, o mesmo texto em outra língua, estudos começam a observar a atuação dos tradutores e consequentemente a diferença que irão produzir, inevitavelmente. Nesse sentido, as questões de fidelidade como uma busca incessante de uma totalidade, de uma apreensão por completo de palavras e pensamentos (atos impossíveis de se concretizarem) são desconstruídas. Frota (2013, p .3) ressalta que, no pós-estruturalismo e inspirados por este momento, estudiosos da tradução "propõem que autores, tradutores e leitores sejam concebidos como sujeitos sociais, sujeitos históricos", e consequentemente, que a língua seja vista quanto ao uso, "ou como um sistema heterogêneo totalmente imbricado com formações culturais e circunstâncias históricas", e não enquanto sistema homogêneo abstrato. Só nesse pequeno conjunto de percepções, Frota (2013, p. 3), então, afirma: "tradução é transformação".

Ao retomarmos questões sobre a visibilidade do tradutor, por exemplo, inevitavelmente também retomaremos as questões de identidade e a construção do sujeito tradutor. Wyke (2010, p. 113) reforça: “ao reconhecer sua visibilidade, tradutores podem começar a refletir de modo mais responsável e realista sobre as relações entre línguas, entre o

\footnotetext{
1 “[...] the fact that translators must decide to orient themselves towards, for example, the source or the target text while striving to reproduce the same text in another language already implies a certain degree of visibility on their part".

Revista de Gestão e Secretariado-GeSec, São Paulo, v. 8, n. 1, p 168-184,jan./abr. 2017.
} 
original e tradução, ou cultura fonte e cultura alvo e examinar seu papel na mediação de culturas" (tradução da autora) ${ }^{2}$. Quando Wyke retrata o papel que o tradutor exerce na mediação de culturas, consequentemente tende a delinear o que o tradutor faz/deve fazer, o que nos remete novamente à construção da identidade do tradutor e, consequentemente, em como secretários executivos recebem esse papel.

Na mesma linha de raciocínio, Rodrigues (2008) salienta, então, que as escolhas feitas pelos tradutores têm seu comprometimento ideológico. Tratar a tradução apenas como substituição de significados de uma língua pelos de outra é ignorar esse comprometimento. Assim, de acordo com a autora, analisar uma tradução apenas sob os aspectos da adequação (seguindo as normas do texto de partida) ou da aceitabilidade (de acordo com as normas da cultura que produz a tradução) é insuficiente. Tal direcionamento não está considerando as escolhas dos tradutores e as relações de poder, ou resistência, envolvidas neste processo. E há ainda outras coisas envolvidas, tais como, para citar apenas uma delas, o contexto de produção. Além disso, essa maneira dicotômica de analisar as coisas, polarizando-as, é, de acordo com Rodrigues (2008), redutora.

Analisando todo o exposto até aqui, percebemos então o quão "problemática" e ao mesmo tempo inspiradora a atividade de traduzir pode ser ("problemática", também, dependendo da perspectiva de análise). Não apenas a atividade em si, mas todo os elementos que se juntam e fazem parte desta atividade social. Neste texto, busco centralizar o sujeito tradutor e o emaranhado de elementos que participam das relações de construção de sua identidade na diferença. Discuto e problematizo diversos conceitos, pensamentos e reflexões sobre a atividade de traduzir na contemporaneidade, especialmente em um momento pósmoderno no qual estudiosos e pensadores desta atividade conseguiram traçar caminhos sob diferentes égides, com foco em especial no sujeito tradutor. Fato é que uma definição/pensamento não consegue excluir elementos de outras definições e pensamentos e os caminhos se entrelaçam, e ao mesmo tempo, em algum momento, se separam. E assim, o sujeito tradutor fluido, conforme descrito por Coracini (2005) em seu estudo, se faz cada vez mais presente e se constrói (ou se desconstrói constantemente, reconstruindo-se na e pela diferença). É inevitável que todos esses elementos irão de alguma forma e em maior ou menor grau afetar a atividade tradutória com todos os elementos envolvidos bem como todos os

\footnotetext{
2 "By acknowledging their visibility, translators can begin to more responsibly and realistically reflect upon the relationships between languages, between the original and translation, or the source and target cultures and examine the role their work plays in cultural mediation."

Revista de Gestão e Secretariado-GeSec, São Paulo, v. 8, n. 1, p 168-184,jan./abr. 2017.
} 
sujeitos que dela participam. Especialmente por ser uma atividade social, obviamente reconstrói também a sociedade como um todo que dela participa.

\subsection{Questões Identitárias para o Secretariado Executivo nas Atividades de Tradução}

Primeiramente, é necessário lembrar que os Estudos da Tradução têm diferentes perspectivas teóricas ao longo de sua história, divergindo em alguns momentos. Para este estudo, parto do pressuposto de que traduzir não diz respeito apenas a uma passagem entre duas línguas. Um tradutor não deve considerar somente as regras estritamente linguísticas, mas também os elementos culturais no sentido mais amplo do termo. (Eco, 2007). Corroborando Eco (2007), Costa (2008) também afirma que "a tradução exige a combinação de conhecimentos linguísticos, culturais e situacionais, para que assim se constitua uma habilidade tradutória" (p. 31).

Dessa forma, ao considerar as questões de identidade, tradução e diferença no ensino de tradução e na formação sobre/em tradução para o Secretariado Executivo, buscamos entender como se constitui o sujeito secretário/tradutor (ou ainda tradutor/secretário). Nos estudos e nas pesquisas na área secretarial, é possível identificar de modo bastante claro a identidade do profissional secretário executivo, não só quanto à sua atividade profissional e rotina de trabalho, mas também analisando o histórico de sua constituição enquanto sujeito profissional e como ele chegou ao que hoje o define, bem como a continuidade ou perspectivas dessas transformações (que não se findam e se redefinem constantemente). Consideramos, então, entender como se dá a construção do sujeito secretário/tradutor, relacionando os estudos e reflexões sobre as configurações da identidade dentro de sua atuação em atividades tradutórias.

Além disso, as questões da construção/constituição da identidade e da diferença na tradução similarmente são latentes e estão em consonância com as questões da construção e da constituição do sujeito profissional de secretariado. Da mesma forma que há a pungência de minorias, questões e relações de poder, além das questões da ética, de gênero, entre outras para os Estudos da Tradução, o mesmo ocorre para o âmbito secretarial. Ambas as atividades, em termos de prática profissional, com anseios e dificuldades muito semelhantes. Em termos de ética profissional, por exemplo, a maneira como Wyke (2010) a descreve para o profissional tradutor é muito semelhante ao descrito no código de ética do Secretariado, regulamentado por lei: ser ético significa ser responsável pelas decisões que toma (Wyke, 
2010). Mesmo considerando a visibilidade do tradutor, por exemplo, o mesmo deve obedecer a algumas regras, inevitavelmente: convenções culturais, gênero, contexto histórico etc. (assim como o profissional de Secretariado também deve fazer).

Como contribuir, então, para a construção de uma concepção de tradução e de tradutor? Ou ainda, como subsidiar reflexões sobre as teorias de tradução como forma/meio de constituir sua tarefa tradutória? O que significa traduzir para o profissional de Secretariado (meio este que se difere daquele do tradutor profissional)? Em que medida e como considerar o papel do currículo e da universidade nesta formação?

Nesse sentido, e também como propulsora de tais questionamentos e reflexões, a pesquisa de Coracini (2005) nos oferece alguns exemplos. Seu estudo levantou alguns aspectos sobre a construção identitária do tradutor sob diferentes perspectivas e discutiu a figura do tradutor considerando a análise de artigos publicados em periódicos especializados dedicados à tradução: (Tradterm - 1992 a 2001; Cadernos de Literatura em Tradução (n. 1); Trabalhos em Linguística Aplicada (n.19); prefácios de obras traduzidas e de algumas coletâneas de textos sobre tradução). De acordo com Coracini (2005), as questões identitárias tornam-se latentes quando há crise, perda de identidade. Em outras palavras, há uma não definição de identidade. Isso se instaura porque ela se desestabiliza, não é mais fixa, passando pela experiência da dúvida e da incerteza. E, assim, questões como "o que significa ser tradutor? O que significa traduzir? Qual é a relação entre a obra original e a traduzida? Quais concepções de linguagem perpassam a atividade tradutória?" atravessam o sujeito tradutor e, consequentemente, segundo Coracini (2005), este sujeito em transformação complexifica a subjetividade, torna a identidade fluida, imprecisa, fugaz, em movimento e constante transformação, deixando o indivíduo desamparado, solitário. Venutti (2002, p. 151), na mesma linha de raciocínio, ao considerar a tradução uma prática cultural, prevê, também, a mudança social pois "nem os indivíduos, nem as instituições, conseguem ser sempre absolutamente coerentes ou imunes às diversas ideologias [...]". Assim, "a identidade nunca é irrevogavelmente fixa, mas relativa". E o tradutor sofre, então, tais consequências.

Discutir e problematizar a atividade tradutória para o profissional de Secretariado seria, por assim dizer, ficar em um entrelugar. O secretário executivo não é tradutor, mas é, em alguns momentos de sua atividade profissional, impelido a traduzir de diferentes maneiras e considerando, em especial, diferentes elementos dependendo do que é requisitado a traduzir. Além de não ser tradutor profissional, também não tem um caminho de escolha para sua atividade, uma vez que não escolhe traduzir, por exemplo, somente o texto literário, ou o Revista de Gestão e Secretariado-GeSec, São Paulo, v. 8, n. 1, p 168-184,jan./abr. 2017. 
técnico, ou apenas um determinado assunto etc. Só nesse aspecto, o sujeito secretário/tradutor já poderia ser considerado sem identidade e lugar, ou constitutivo de diferentes identidades em diferentes lugares. Ele trabalha, para citar um dos aspectos, com a língua e a linguagem que, conforme discutido sob a perspectiva de Rajagopalan (1998), não pode ser considerada homogênea muito menos utilizada por falantes ideais. Ou seja, ele (o secretário/tradutor), o texto com o qual ele trabalha, o texto que irá produzir e o local do qual ele participa (a empresa) ou os sujeitos com os quais ele se envolve (sua hierarquia ascendente e descendente em termos de organograma empresarial) estão embebidos em ideologias diversas e não podem ser considerados, de maneira alguma, neutros. Sendo assim, discutir e problematizar a constituição da identidade deste sujeito com atividades ora diferentes ora similares, tem suma importância, quer seja no âmbito da pesquisa ou da formação (na graduação). Especialmente porque é na e pela diferença que ele irá se constituir.

Considerando, então, o possível entrelugar no qual se encontra o profissional de Secretariado Executivo nas atividades tradutórias, faz-se necessário uma reflexão. Para tanto, foi conduzida a análise dos dados.

\section{PROCEDIMENTOS METODOLÓGICOS}

A presente pesquisa tem por objetivo analisar questões identitárias na formação do profissional de secretariado para atividades tradutórias.

Primeiramente, foi realizada uma revisão bibliográfica com o propósito de identificar, conceituar e refletir sobre as questões subjacentes à pesquisa aqui apresentada. A etapa da revisão bibliográfica é importante porque apresenta os dados já abordados por outros autores, demonstrando a contribuição e a relevância da pesquisa realizada.

Quanto à natureza, a pesquisa é de cunho aplicado, uma vez que busca gerar conhecimentos para aplicação prática, dirigidos à solução de problemas específicos (Prodanovi \& Freitas, 2013) ou a compreensão de fenômenos e situações práticas. É do mesmo modo exploratória, de caráter qualitativo-descritivo e visa demonstrar em sua análise como secretários executivos se percebem frente a atividades tradutórias. Assim, o objeto deste estudo são os alunos de um curso de graduação de Secretariado Executivo de uma instituição de ensino superior do norte do Paraná. 
A coleta dos dados para análise se deu por meio de questionários respondidos pelos alunos. O questionário era constituído de questões abertas e fechadas, visando a percepção sobre as questões identitárias do futuro profissional secretário/tradutor, foco do estudo.

\section{RESULTADOS E DISCUSSÕES}

O objetivo deste estudo foi explorar as percepções sobre as atividades de tradução para o Secretariado Executivo dos alunos ingressantes, ou seja, alunos do $1^{\circ}$ ano do curso.

A escolha pela aplicação do questionário para tal grupo se justifica para observar quais percepções tinham tanto sobre o universo secretarial quanto o universo tradutório - ambos novos para esses respondentes.

Ao todo, 25 questionários foram respondidos. As questões foram divididas em duas etapas: na primeira, eram de cunho descritivo e de conceituação de elementos de forma direta (o que é...?); na segunda, a conceituação é específica e contextualizada - para o âmbito no qual eles participam.

Primeiramente, nas questões abertas, sobre a percepção dos alunos ingressantes quanto ao que é ser um secretário executivo, a descrição se deu basicamente sob a seguinte perspectiva: é um facilitador dentro da empresa, possuidor de diferentes habilidades e conhecimentos, assessor, e participante de processos decisórios.

$\mathrm{Na}$ sequência, foi também questionado nas perguntas abertas sobre o que seria um profissional tradutor. $\mathrm{Na}$ análise das respostas, foi possível resumi-las com a seguinte descrição: é aquele que traduz documentos, que tem a capacidade de converter textos, de se comunicar e expressar a mesma ideia em diferentes idiomas, capacidade de intermediar dois idiomas e duas culturas diferentes, colaborador da comunicação local, aquele que torna a compreensão possível. Nas respostas, percebemos os primeiros elementos que se sobressaem na construção da "identidade do tradutor": línguas, comunicação, facilitador da compreensão.

Na segunda etapa, a primeira questão aberta foi se o secretário executivo poderia ser requisitado a traduzir, ou seja, fazer atividades de tradução, em algum momento de sua rotina diária de trabalho. Com essa pergunta, a intenção foi descobrir se algum dos alunos teria dúvidas sobre a atividade tradutória estar inserida em seu escopo de trabalho. Porém, as respostas foram unânimes e afirmativas que sim, um secretário executivo poderá ser requisitado a fazer uma tradução ou atividade que envolva tradução em seu local de trabalho. Tal unanimidade imprime a identidade de um "secretário/tradutor", ou seja: se secretários 
executivos são requisitados a atuar como tradutores, ideologicamente configura-se uma imagem, uma representação do que seria, o que constitui esse profissional.

Desse modo, como desdobramentos da questão anterior, um dos objetivos foi explorar a real percepção dos alunos sobre o que significa traduzir para eles enquanto futuros secretários. Questionou-se quais conhecimentos o secretário executivo necessita para executar atividades tradutórias. Os alunos, de modo geral, responderam que precisam saber muito bem o idioma para o qual farão as traduções, além de ter fluência na escrita, conhecer métodos/técnicas de tradução, saber bem a língua materna, ter boa interpretação, saber vocabulário e saber argumentar. Nas respostas, alguns aspectos interessantes são evidenciados. Em um primeiro momento, os respondentes se pautam em questões de cunho linguístico, e relacionam não só o idioma estrangeiro mas também sua língua materna como importantes no processo tradutório. Em um segundo momento, relatam que precisam do conhecimento das técnicas e métodos de tradução. Assim, é claro para os alunos que apenas saber os idiomas envolvidos não os prepara para fazer traduções. Eles necessitam de conhecimentos específicos da área, assim como precisam dos conhecimentos de gestão para atuarem como secretários nos diferentes âmbitos das organizações empresariais. Além disso, dos 25 respondentes, apenas dois mencionam que seria necessário ter um curso/especialização específico na área de tradução, ou seja, posterior ou em paralelo à graduação. É possível, então, dizer que os alunos em sua grande maioria desejam e esperam obter conhecimentos sobre as atividades tradutórias ainda na sua graduação em secretariado. Apesar de usarem os termos "métodos" e "técnicas" de tradução que restringem a atividade a aspectos estruturalistas, não alcançando a complexidade de tudo que envolve o ato de traduzir, os alunos ingressantes percebem a necessidade de um mínimo de subsídio teórico e prático para a constituição dessa possível identidade de "secretário/tradutor".

Uma última questão foi se secretários executivos poderiam ser considerados tradutores, ou seja, se poderiam atuar como tradutores, substituindo profissionais tradutores. A questão levantada se deu para percepção de uma problemática sofrida por tradutores e que igualmente secretários executivos sofrem em sua atuação profissional: de que qualquer indivíduo, independente de sua formação, pode ser um tradutor ou também um secretário. Sabemos da luta para regulamentação da profissão e exigência da formação para o secretariado, apesar do direcionamento contrário dado pelo mercado de trabalho quando oferta vagas para graduados em administração, letras, turismo etc. Da mesma forma, a problemática da falta de formação para tradutores é também de preocupação em seu mercado 
de atuação. O desejo era compreender se o secretário executivo consideraria atuar como tradutor, mesmo não tendo a formação da graduação em tradução. As respostas para essa questão foram adversas.

Dos 25 respondentes, oito consideraram que não poderiam ser considerados tradutores, e a justificativa foi de que nem todo secretário executivo é capaz de fazer traduções, primeiro por serem duas funções distintas, além de o profissional necessitar da formação e especialização na área e por fim, por serem áreas diferentes. O restante dos respondentes, ou seja, 17, responderam que poderiam ser considerados tradutores uma vez que estudam idiomas estrangeiros e que são ensinados e conhecem métodos e técnicas de tradução. Alegam, também, que o curso de secretariado oferece conhecimento qualificado para atividades tradutórias. Tal afirmação se dá porque o curso na instituição pesquisada oferece disciplina de tradução no último ano, ou seja, generalizaram tomando por base o contexto no qual estão inseridos. Porém, sabemos que essa não é a realidade em âmbito nacional. Além disso, quatro desses 17 últimos respondentes, apesar de terem respondido afirmativamente sobre secretários poderem atuar como tradutores substituindo esses profissionais, na justificativa de suas respostas disseram que a atuação como tradutor dependeria, em especial, pela necessidade de estes secretários executivos se especializarem/aprofundarem seus conhecimentos sobre tradução. Ou seja, alegam que podem atuar no lugar de tradutores profissionais, mas reconhecem que precisam se especializar. Lembrando que na questão anterior, essa "especialização" ou necessidade de conhecimentos mais aprofundados já havia sido evidenciado por dois respondentes. Isso identifica a construção identitária instável pelo momento que estão passando (fase inicial, embrionária de formação), o que, de acordo com o embasamento teórico deste estudo, é aceitável, pois implica um ir e vir de conceitos, características e outros elementos para essa constante construção.

Também conforme exposto anteriormente, possivelmente quando usam os termos “especializar”, “aprofundar” em suas respostas, estão se remetendo a conhecer mais sobre a área tradutória paralelamente à graduação ou após sua conclusão, na forma de cursos de pósgraduação lato sensu, outra graduação de bacharelado em tradução etc. Há ainda um respondente que, para justificar sua resposta, levanta um ponto importante e diz: "Sim (o secretário executivo poderia ser considerado um tradutor), mas depende. Se o curso de formação do secretário tiver oferecido conhecimentos em língua e na área de tradução (como na instituição pesquisada), sim.” Percebemos, com essa justificativa, que os alunos realmente consideraram que todos ou a grande maioria dos cursos de graduação em Secretariado 
Executivo oferecem, em sua matriz curricular, disciplinas ou conteúdos sobre ou relacionados à área tradutória.

Porém, em dados quantitativos que estão sendo ainda levantados, coleta de dados iniciada em 2015 (em andamento), dos 48 cursos já pesquisados, apenas quatro oferecem esses conhecimentos (conteúdos sobre ou disciplinas de tradução), sendo um deles a instituição pesquisada. Isso seria apenas $10 \%$ da formação em abrangência nacional. Assim, é possível que secretários executivos estejam adentrando o mercado de trabalho com a falsa percepção identitária de que podem atuar como tradutores quando, na verdade, não podem. Apenas conhecimento linguístico não os tornará aptos a realizarem traduções, conforme problematizada neste estudo a complexidade da atividade tradutória. Temos, assim, uma questão preocupante em uma formação secretarial que carece de embasamento para uma atuação mais completa por parte dos novos profissionais.

\section{CONSIDERAÇÕES FINAIS}

Questões identitárias nos levam a refletir sobre o que significa ser tradutor para o Secretariado Executivo e o que significa também traduzir para esses profissionais, tema relevante para a formação. Com o objetivo de observar a construção de uma identidade para um "secretário/tradutor", foi aplicado questionário sobre o assunto para alunos ainda na graduação.

É perceptível que os alunos que acabaram de iniciar o curso de Secretariado Executivo (ingressantes) na instituição pesquisada e que ainda não se envolveram com os conhecimentos secretariais, possuem uma percepção social mais generalista, do senso comum, tanto sobre o universo secretarial quanto sobre a atividade tradutória. Essa percepção nesse recorte da atualidade (início da graduação) lhes oferece uma identidade daquilo que conhecem hoje. Certamente essa identidade será mudada no decorrer da transformação de seu conhecimento, transformação esta que se dará dentro de sala de aula e com o contato com os colegas, nos conteúdos aprendidos, com as empresas e as pessoas com as quais irão trabalhar em seu estágio, com comunidades específicas, entre outros.

Quanto à percepção sobre tradução, fica claro que há dúvidas e mais desconhecimento sobre a percepção e construção dessa identidade. Porém, da mesma forma que a identidade do secretário executivo será transformada, a do tradutor dentro do universo secretarial também 
será, em especial por experiências que vivenciarão na universidade e também em seus estágios extra e curriculares.

O aspecto positivo deste estudo é a percepção de que alguns alunos já reconhecem a necessidade de conhecerem mais e se aprofundarem nos estudos e conhecimentos tradutórios. Porém, a dúvida é como esse conhecimento será ensinado, discutido para a formação no âmbito secretarial. Os Estudos da Tradução fornecem embasamento para a atividade tradutória. Creio que o grande desafio é como os Estudos da Tradução podem subsidiar a formação em tradução para secretários executivos. Desafio ainda maior é demonstrar ao meio acadêmico secretarial a importância dessa perspectiva na formação de futuros secretários executivos. Espero, com este estudo, ter contribuído em um caráter inicial para tal discussão e reflexão.

\section{REFERÊNCIAS}

Coracini, M. J. (2005). Discurso sobre tradução: aspectos da configuração identitária do tradutor. Tradterm, n.11, pp. 29-51.

Costa, A. P. A. T. da (2008). Traduzir para comunicar: a tradução como componente no ensino-aprendizagem de inglês como língua estrangeira. Dissertação de mestrado, Universidade de Brasília.

Eco, U. (2007). Quase a mesma coisa. Rio de Janeiro: Record.

Frota, M. P. (2013). A escrita do inconsciente no texto traduzido. Revista Escrita, n. 17 , pp. $1-15$.

Hall, S. (2001). A identidade cultural na pós-modernidade. Rio de Janeiro: DPA.

Prodanov, C. C. \& Freitas, E. C. de (2013) Metodologia do trabalho científico: métodos e técnicas da pesquisa e do trabalho acadêmico (2a ed.). Novo Hamburgo: Feevale. 
Rajagopalan, K. (1998).O conceito de identidade em Linguística: é chegada a hora para uma reconsideração radical? In: Signorini, I. (org.) Lingua(gem) e identidade. Campinas: Mercado de Letras, p. 21-45.

Rodrigues, C. C. (2008). A ética da apropriação. Tradução e Comunicação - Revista Brasileira de Tradutores, n.17, pp 21-28.

Silva, T. T. da et al. (org.) (2012). Identidade e diferença: A perspectiva dos estudos culturais. Petrópolis: Vozes.

Venutti, L. (2002). Escândalos da Tradução. Bauru: Edusc.

Wyke, B. V. (2010) Ethics and Translation. Handbook of Translation Studies. vol. 1, John Benjamins Publishing Company. 